\title{
Research on the Management of Scientific Research Funds in Colleges and Universities-Taking College $A$ as an Example
}

\author{
SHI XIAO \\ Beijing Jiaotong University, China \\ 18362087631@163.com \\ SHI XIAO
}

Keywords: University, Research Funding, Management.

\begin{abstract}
With the continuous expansion of the scale of colleges and universities in China and the continuous deepening of the reform of the teaching system in colleges and universities, the problems in the financial management of colleges and universities have become increasingly prominent. Among these problems, the problems in the management of scientific research funds are the most prominent. Therefore, how to strengthen the management of scientific research funds is another important topic in the financial management of colleges and universities. Based on the current situation of research funding management in colleges and universities, this paper takes college A as an example, analyzes the specific problems such as inadequate budget management, loose management of surplus funds, and imperfect performance incentive mechanism, and proposes corresponding improvement measures to solve these problems.
\end{abstract}

\section{Introduction}

In recent years, China has continued to implement the strategy of innovation-driven development. The fiscal technology investment has maintained rapid growth in successive years, providing a strong guarantee for the improvement of innovation strength. On August 30, 2019, the National Bureau of Statistics, the Ministry of Science and Technology, and the Ministry of Finance jointly issued the "Statistical Bulletin on National Science and Technology Funds Investment in 2018". The "Gazette" shows that the national financial science and technology expenditure in 2018 was 951.82 billion yuan. According to the "Gazette", the national financial science and technology expenditure in 2018 was 951.82 billion yuan, which has increased by $13.5 \%$ than that of last year. At the same time, the state increased its policy support for research and experimental development (R\&D) activities and guided all parties to increase R\&D investment. The "Gazette" also showed that the total investment in R\&D was 1967.79 billion yuan in 2018, which has increased by $11.8 \%$, ranking second in the world[1]. As the important executives of research funding, colleges and universities are the main force of scientific and technological innovation, shouldering the important mission of personnel training, scientific research and social services. Under the strong support of the state for scientific research, colleges and universities have also achieved considerable scientific research results[2].

However, the problems of budget management and performance management in the management of scientific research funds are still quite prominent. Cases of violation of laws and regulations also occur from time to time [3]. Therefore, how to use and manage scientific research funds more scientifically and rationally is an important issue faced by colleges and universities.

\section{The current situation of research funding management of colleges $A$}

\subsection{Research funding management agency of college A}

There are two competent departments for scientific research work in colleges A, the Science and Technology Department and the Social Science Department, which are jointly responsible for scientific research project management and contract management, and cooperate with the Finance Department to do a good job in research funding management. The Science and Technology Department is mainly responsible for organizing the preparation of school science and technology 
planning and formulating school science and technology policies and rules and regulations. It is responsible for organizing the school's scientific and technological strength to undertake various scientific and technological projects. The Social Science Department is a comprehensive functional department responsible for the planning, management and service of humanities and social sciences in the whole school. It is responsible for formulating the development plan of the humanities and social sciences of the school and organizing the implementation, promoting the construction of the liberal arts department and the reform of the scientific research system.

\subsection{The current situation of research funding income}

The research funding sources of college A mainly include government funds, enterprises and institutions entrusted funds and other funds, Among which government funds and enterprises and institutions entrusted funds are the most important source. According to the statistics of science and technology of higher education institutions of the Ministry of Education of the Ministry of Education from 2013 to 2017, the income of research funds from A colleges and universities in 2013 to 2017 was counted (as shown in Table 1). It can be seen from the table that the income of scientific research funds of college A has increased year by year, and the income of research funds in 2014 and 2015 has decreased slightly. This is because the research funding from government funds has decreased a lot in the past two years. The amount was 630.55 million yuan and 558.472 million yuan respectively, which was 658.05 million yuan and 71.583 million yuan respectively lower than the previous year[1].

Table 1. research funding income in college A from 2013 to 2017 (Unit: 10,000 yuan)

\begin{tabular}{cccccc}
\hline & 2013 & 2014 & 2015 & 2016 & 2017 \\
\hline Government funds & 695860 & 630055 & 558472 & 658465 & 812044 \\
\hline Entrusted funds by enterprises and institutions & 807745 & 827163 & 946850 & 968240 & 974144 \\
\hline Other sources & 22210 & 21400 & 10174 & 36545 & 16161 \\
\hline Total income from research funding & 1525815 & 1478618 & 1515496 & 1663250 & 1802349 \\
\hline
\end{tabular}

\subsection{The current situation of research expenditures}

The research funds obtained by college A are mainly used in the following aspects: labor costs, business expenses, transfer units and other expenses, of which business expenses are the most important, followed by labor expenses and other expenses. According to the statistics of the research and development expenditures of A colleges and universities in the past five years (as shown in Table 2 ), the total expenditure of scientific research funds in 2013-2017 is increasing. Among them, the total expenditures in 2015 and 2016 decreased slightly, it mainly because the expenditures of the units outside the transfer have undergone great changes. Since 2014, the expenditure has decreased significantly. The amount of expenditure in 2014 was 637.82 million yuan, which has decreased by 192,837 compared with 2013, the reduction ratio is 75.15\%. In 2016 and 2017, research expenditures increased significantly, it mainly due to the significant increase in Service fee in 2016[1].

Table 2. research expenditures in college A from 2013 to 2017 (Unit: 10,000 yuan)

\begin{tabular}{cccccc}
\hline & 2013 & 2014 & 2015 & 2016 & 2017 \\
\hline Labor costs & 311711 & 256009 & 352274 & 353733 & 451642 \\
\hline Service fee & 513329 & 656005 & 679941 & 911083 & 866446 \\
\hline Transfer outside unit & 256619 & 63782 & 58369 & 60883 & 89238 \\
\hline Other expenses & 260521 & 351243 & 212049 & 250786 & 263692 \\
\hline Total expenses & 1342180 & 1327039 & 1302633 & 1576485 & 1671018 \\
\hline
\end{tabular}

\section{Defects in the management of scientific research funds in college A}

\subsection{Budget management is not in place}

Budget preparation is the starting point for the management of scientific research funds. The budget preparation for scientific research projects of college $\mathrm{A}$ is the responsibility of the principal investigator. Once the project budget is approved by the competent department, it is generally not adjusted. The project leader must strictly follow the budget prepared in advance. Therefore, whether 
the budget preparation is scientific and reasonable has a great impact on the research projects of scientific research workers. However, in fact, most project leaders often only rely on personal experience and subjective judgment in the process of budget preparation, and the budget preparation is arbitrarily large, which leads to the lack of scientific budgeting, which ultimately leads to difficulties in the implementation of scientific research projects. Moreover, the research funding of college A is used in competition throughout the school. When the use of school funds reaches the upper limit of the national treasury, all funds will be discontinued. In order to obtain more research funding, some project leaders will even count the expenses unrelated to the research of tourism and entertainment, and deliberately exaggerate expenses.

\subsection{The management of the balance funds is relatively loose}

According to the latest scientific research fund management method of college A, after the completion of the longitudinal scientific research project (scientific research grant), if there is a surplus fund, it should be used in accordance with the regulations of the competent department for scientific research grants. After the completion of the horizontal research funding (revenue from scientific research), the surplus fund can be used by the project leader to support the maintenance and operation of equipment, personnel training, and other research and development projects, and can also be used for business. There are no restrictions on the amount and proportion of specific expenditures for negotiating hospitality fees, graduate student assistants, and other expenses. After some scientific research projects have been completed and passed the acceptance, the balance have not been transferred in time. The phenomenon of not closing the accounts is very common, and the management of the surplus fund lacks a corresponding tracking mechanism.

\subsection{The performance incentives are not perfect}

The role of scientific research personnel in the implementation of scientific research projects is the most important. They have paid a lot of labor in the scientific research process. It is reasonable to say that they should receive corresponding rewards and rewards. However, according to the scientific research management regulations of college A, there are wage income. Participants in the project are not allowed to pay labor costs. Only the researchers who are temporarily employed and the relevant R\&D personnel who do not have wage income, such as postgraduate students, postdoctoral fellows, visiting scholars, etc., can be listed in the budget. According to the "Several Opinions on Further Improving the Fund Management of Central Financial Research Projects" issued by the General Office of the State Council, labor costs have been removed, but in fact, major universities will set a proportional limit in the process of budget preparation. The proportion of labor expenses in college A has increased in recent years, from $23.2 \%$ in 2013 to $27.03 \%$ in 2017. But it is still not proportional to the brainpower of researchers. In addition, the proportion of performance expenditures of scientific research projects is only $5 \%$, the difference between the quality of project completion is small, and the performance appraisal is not fully reflected.

\section{Suggestions on improving the management of scientific research funds}

\subsection{Establish a scientific and rational budget management system}

The budget of scientific research projects is different from the engineering budget. It has the characteristics of exploratory and uncertain. In the process of budget preparation, it is necessary to prevent the preparation from being both too rough and too detailed[4]. If the preparation is too rough, the budget assessment needs will not be met, and the budget of the project cannot be reasonably verified. The preparation of the fine will increase the additional burden on the researchers. Budgeting should follow the principle of three principles: target relevance, policy compliance, and economic rationality. At the same time, relevant departments should also decentralize budget adjustment authority. Due to the uncertainty of scientific research projects, budgeting is also a very headache for researchers. Once an experiment fails, it will be reinstated and new equipment and materials will be purchased. If the researcher has to go on a business trip, it will increase the travel expenses. These 
expenses are unpredictable, and if there is an unexpected situation, it will lead to a big difference between actual expenditure and budget. Therefore, it is necessary to define the detailed items of "indirect costs". Both the United Kingdom and the United States have clearly defined the items that can be included in the indirect costs, including various resource occupation fees, operation and maintenance fees, and management fees. The United Kingdom has also specifically identified "unforeseen expenses", which are caused by uncertain factors such as temporary academic exchanges and price adjustments[5]. It can reflect the value compensation of scientific research projects for the public resources occupied, and can also accurately verify its proportion in the cost structure of research funding.

\subsection{Strengthen the management of the balance of the project}

Colleges and universities should combine the actual situation of the school and formulate specific management measures in accordance with the relevant policies formulated by the Ministry of Education, so that the school's scientific research funds management departments and project leaders can be implemented in accordance with regulations. In principle, the person in charge of the project must arrange expenditures reasonably, minimize the balance of funds, and must not use and transfer the surplus funds in violation of regulations. For the funds of the central financial research project, the research project shall be completed and approved for full recovery after two years of acceptance. For those funds that can be used by other universities for scientific research activities, the project leader shall submit an application for the research fund according to the research needs. Then, the Finance Department will co-ordinate the balance funds to the Research Pre-Research Fund according to the materials provided by the School Scientific Research Office. If the person in charge of the project does not handle the financial settlement on time, the balance shall be used by the school.

\subsection{Improve incentive mechanism and performance evaluation system}

According to regulations[5], graduate students, post-doctoral fellows, visiting scholars, and researchers and research assistants who participate in research projects can spend labor costs. College A should increase the proportion of labor expenses for scientific research funds on the original basis, and fully recognize the labor value of scientific research personnel[7]. This can create an academic ecological environment conducive to scientific research for scientific research personnel, so that researchers who are really labored can obtain the return, it can also reduce the phenomenon of a small number of people taking illegal research funds to some extent. In addition, colleges A should further clarify the scope and standards of labor expenses, so that the staff of relevant departments can be implemented in actual work. When evaluating scientific research results, it is necessary to establish a scientific research performance evaluation system based on high-level achievements and high-level talents[8], comprehensively consider the economic and social benefits of scientific research projects, and combine the scientific research personnel's performance evaluation on the basis of performance evaluation of scientific research work.

\section{Conclusion}

In summary, this paper takes college $\mathrm{A}$ as an example, analyzes the specific problems such as inadequate budget management, loose management of surplus funds, and imperfect performance incentive mechanism, and proposes corresponding improvement measures. Research funding is an important basis for ensuring the smooth progress of scientific research projects. Whether the management of scientific research funds is scientific and whether the use of scientific research funds is reasonable directly affect the quality of scientific research and the level of scientific research. Only by actively carrying out innovations in the management of scientific research funds, can we maximize their effectiveness and greatly enhance the enthusiasm of researchers, thus promoting the overall development of school research. 


\section{References}

[1] Department of Science and Technology of the Ministry of Education, Compilation of scientific and technical statistics of higher education institutions (2013-2017). website of the Science and Technology Department http://www.moe.gov.cn/s78/A16/.

[2] M. Zhao, K. Li. An Empirical Study of the Influence of University Funds Income on Scientific Research Output, Education Monthly, pp. 43-48, 2014.

[3] Y. Fu and J. Yang, The Roots and Governance of the Use of Scientific Research Funds in Colleges and Universities. Research and Development Management, vol.26, pp. 116-121, 2014.

[4] S. Z. Yang, G. Y. Zhang, Y. Q. Luo and H. N. Zhu, Game Analysis of Budget Management of Financial Research Projects in Colleges and Universities under the Background of "Public Suits", Science and Technology Management Research, vol.39, pp. 88-96, 2019.

[5] A. Huang. Comparative Analysis and Enlightenment of Scientific Research Fund Management in Britain, America and China, Friends of Accounting, vol.597, pp. 27-30, 2018.

[6] The General Office of the Central Committee of the Communist Party of China, the General Office of the State Council, "Several Opinions on Further Improving the Fund Management of the Central Financial Research Projects", Xinhua News Agency, 2016,

[7] B. R. Clark, Scientific Research Team of University Incentive Mechanism Research, Social Science, pp. 245, 2007.

[8] W. M. Liu, M. Yang, Z. M. Yi, Y. D. Yang, Research on Accountability of Vertical Research Funds in Colleges and Universities_-Based on Principal-Agent Theory, Friends of Accounting, pp. 69-72, 2017 